\title{
Reproductive performance of early- and late-calving dairy cows artificially inseminated after ovulation synchronization and estrous resynchronization or artificially inseminated after observed estrus
}

\author{
S. G. Moore, ${ }^{1 *} \odot$ S. A. Hamilton, ${ }^{1}$ R. Molina-Coto, ${ }^{1} \dagger \odot$ L. M. Mayo, ${ }^{1} \neq \odot$ R. O. Rodrigues, ${ }^{1} \odot$ T. Leiva, ${ }^{1}$
} S. E. Poock, ${ }^{2}$ (1) and M. C. Lucy ${ }^{1} \S \odot$

\section{Graphical Abstract}

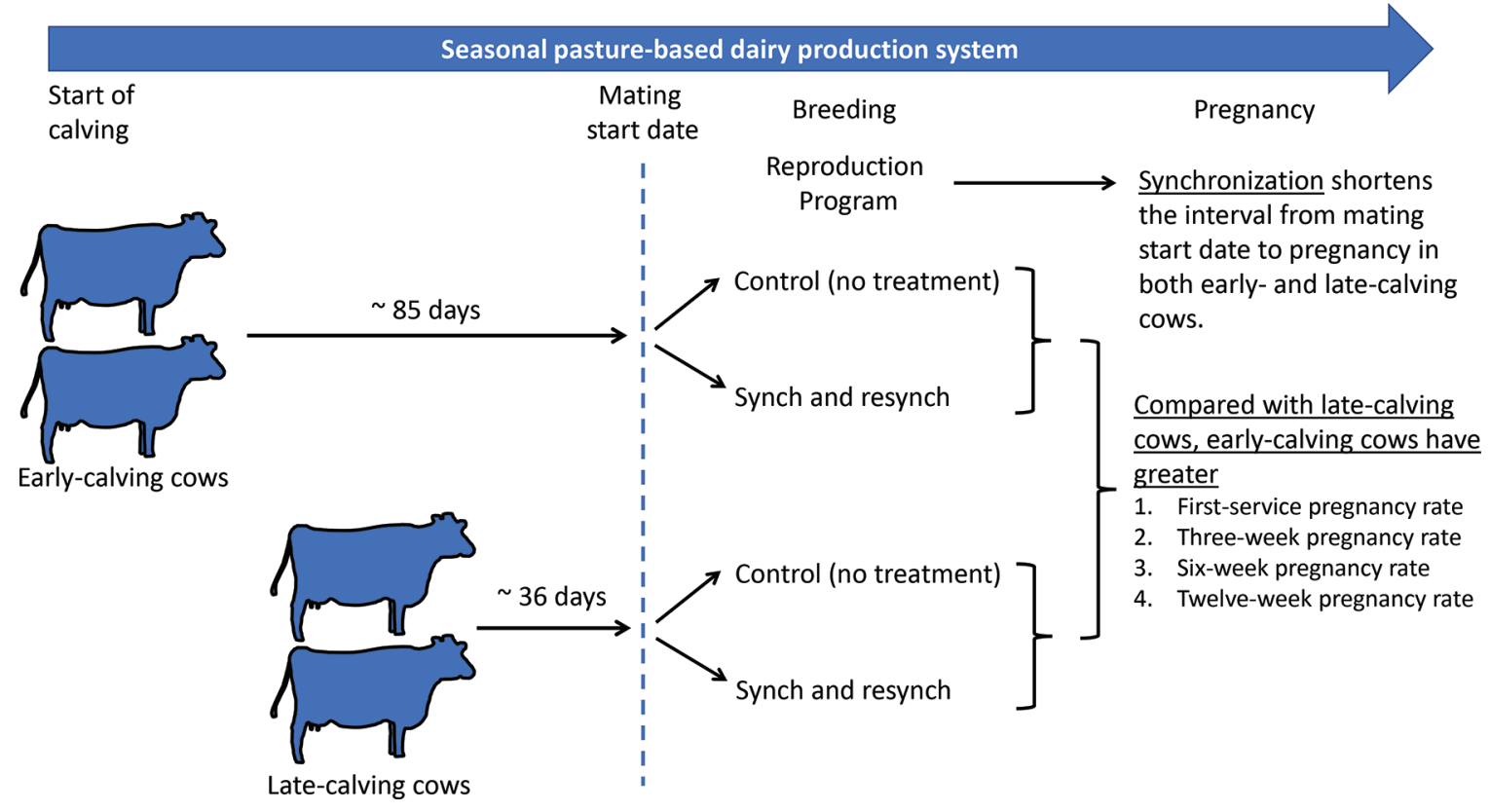

\section{Summary}

Cows that calve late in the calving season are less likely to become pregnant and maintain a yearly calving interval for pasture-based dairies because they are too few days postpartum at the start of breeding (mating start date). We found that late-calving cows had poor reproductive performance compared with early-calving cows. Nonetheless, a major improvement to reproductive performance was achieved by targeting late-calving cows with a synchronization program.

\section{Highlights}

- Late-calving cows had lesser fertility than cows that calved early in the calving season

- An Ovsynch program with progesterone (P4) improved reproductive performance for both early- and late-calving cows

- A Resynch program based on P4 supplementation alone and Al after detected estrus failed to improve second Al submission rates

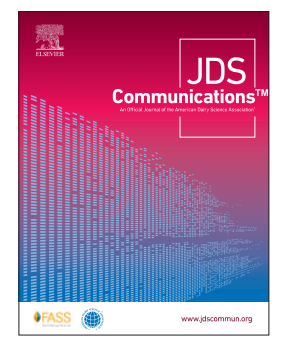

'Division of Animal Sciences, University of Missouri, Columbia $65211,{ }^{2}$ College of Veterinary Medicine, University of Missouri, Columbia $65211 .{ }^{*}$ Current address: Animal and Grassland Research and Innovation Centre, Teagasc Moorepark, Fermoy, Co. Cork, P61 P302, Ireland. +Current address: Universidad de Costa Rica, Escuela de Zootecnia, San José 1501-2060, Costa Rica. ‡Current address: Integrative Biosciences PhD Program, Tuskegee University, Tuskegee, AL 36088. §Corresponding author: lucym@missouri.edu. @ 2021, The Authors. Published by Elsevier Inc. and Fass Inc. on behalf of the American Dairy Science Association ${ }^{\circledast}$. This is an open access article under the CC BY license (http://creativecommons.org/licenses/by/4.0/). Received October 02, 2020. Accepted November 30, 2020. 


\title{
Reproductive performance of early- and late-calving dairy cows artificially inseminated after ovulation synchronization and estrous resynchronization or artificially inseminated after observed estrus
}

\author{
S. G. Moore, ${ }^{1 *} \odot$ S. A. Hamilton, ${ }^{1}$ R. Molina-Coto, ${ }^{1} \dagger \odot$ L. M. Mayo, ${ }^{1} \neq \odot$ R. O. Rodrigues, ${ }^{1} \oplus$ T. Leiva, ${ }^{1}$ \\ S. E. Poock, ${ }^{2}$ (1) and M. C. Lucy ${ }^{1} \S \odot$
}

\begin{abstract}
Within seasonal dairy systems, cows that calve late in the calving season are less likely to become pregnant and maintain a yearly calving interval. Very few studies have examined effective strategies for reproductive management of these late-calving cows. The objectives were to evaluate the reproductive performance of early- and late-calving dairy cows that were either inseminated after observed estrus (control) or enrolled in a timed AI and resynchronization protocol [progesterone (P4) Ovsynch Resynch)]. Early-calving cows calved during the first week of the calving season, whereas late-calving cows calved after 6 wk but were at least $10 \mathrm{~d}$ in milk at study commencement. Three dairy herds participated in the study with 391 cows total. Within each calving group, cows were randomly assigned to P4 Ovsynch Resynch or control (no treatment) in a $2 \times 2$ experimental design. Artificial insemination continued for 6 wk after mating start date (MSD) and was followed by $6 \mathrm{wk}$ of natural service. The interval from MSD to AI was shorter (11.7 vs. $14.7 \mathrm{~d}$ ) and the 3 -wk pregnancy rate (49.5 vs. $21.2 \%)$ and the 6-wk pregnancy rate $(60.8$ vs. $42.4 \%)$ were greater in the early-calving compared with the late-calving control cows. By design, synchronized cows received timed AI on MSD and were not included in the statistical analysis of submission rate and interval from MSD to AI. The proportion of cows that received a second AI was not increased by the progesterone-based resynchronization strategy but was greater in early-calving compared with late-calving cows. The 12-wk pregnancy rate was greater (64.5 vs. $45.0 \%)$ in the early-calving synchronized cows compared with the late-calving synchronized cows. The interval from MSD to pregnancy was 6 and $12.6 \mathrm{~d}$ shorter for synchronized compared with control cows in the early- and late-calving groups, respectively. The results demonstrated reduced reproductive performance of late-calving cows compared with early-calving cows. Nonetheless, a major improvement to reproductive performance was achieved by targeting late-calving cows with a synchronization program, even when cows were only 20 to 50 DIM at first AI. Resynchronization of estrus with a progesterone device only, however, was not sufficient to increase the proportion of nonpregnant cows that received a second AI.
\end{abstract}

E cellent reproductive performance, defined primarily as a 3-wk submission rate of at least $90 \%$, a 6 -wk lactating cow pregnancy rate of at least $70 \%$ (Butler, 2014), and a 6-wk herd calving rate of $90 \%$ is critical to the efficient and profitable operation of seasonalcalving, pasture-based dairy herds (Shalloo et al., 2014). Failure to achieve these targets can be largely attributed to cows that do not calve during the first $6 \mathrm{wk}$ of the calving season (late-calving cows). Late-calving cows are less likely to establish pregnancy during the first $6 \mathrm{wk}$ of the breeding season because of the reduced time available to complete uterine involution, resume ovarian cyclicity, and express estrus.

Estrous synchronization protocols have evolved to facilitate first insemination timed AI without the need for estrous detection, but pregnancy rates were low in earlier studies that used the Ovsynch protocol (Cordoba and Fricke, 2002). Pregnancy rates, especially in anestrous cows, are greatest when progesterone (P4) is supplemented for the first 7 to $8 \mathrm{~d}$ of the Ovsynch protocol (Herlihy et al., 2011; Rojas Canadas et al., 2019). Resynchronization protocols have been developed to facilitate the AI of previously inseminated cows that are nonpregnant. One such protocol uses P4 administration via an intravaginal insert from 14 to $21 \mathrm{~d}$ after the first AI. This approach reduces the number of days required for estrous detection; however, only cows that are detected in estrus can be inseminated (Chenault et al., 2003; Chebel et al., 2006). Pregnancy rates in dairy cows improve when the number of completed estrous cycles and DIM at first AI increases (Thatcher and Wilcox, 1973; Britt, 1975; Herlihy et al., 2011; Rojas Canadas et al., 2019). Latecalving dairy cows are typically not enrolled in first-service timed $\mathrm{AI}$ and resynchronization programs because they are thought to be too early postpartum to benefit from these strategies.

The primary objective was to evaluate the reproductive performance in late-calving cows compared with early-calving cows inseminated after observed estrus or enrolled in a first-service timed AI and resynchronization protocol (P4 Ovsynch Resynch). The primary hypothesis was that reproductive performance would

\footnotetext{
${ }^{1}$ Division of Animal Sciences, University of Missouri, Columbia $65211,{ }^{2}$ College of Veterinary Medicine, University of Missouri, Columbia $65211 .{ }^{*}$ Current address: Animal and Grassland Research and Innovation Centre, Teagasc Moorepark, Fermoy, Co. Cork, P61 P302, Ireland. †Current address: Universidad de Costa Rica, Escuela de Zootecnia, San José 1501-2060, Costa Rica. ‡Current address: Integrative Biosciences PhD Program, Tuskegee University, Tuskegee, AL 36088. §Corresponding author: lucym@missouri.edu. @ 2021, The Authors. Published by Elsevier Inc. and Fass Inc. on behalf of the American Dairy Science Association ${ }^{\circledast}$. This is an open access article under the CC BY license (http://creativecommons.org/licenses/by/4.0/). Received October 02, 2020. Accepted November 30, 2020.
} 
be improved in cows enrolled on the P4 Ovsynch Resynch protocol regardless of their calving group.

Three commercial pasture-based dairy farms located in the southwest region of Missouri participated in the study from April to July 2016. Each herd grazed a mixture of perennial ryegrass and fescue pastures and was supplemented twice daily during milking with ground corn. The early-calving group consisted of cows that calved during the first week of each herd's calving season. The late-calving group consisted of cows that did not calve during the first 6 wk of each herd's calving season and were at least 10 DIM at study commencement.

A total of 391 cows were enrolled in the study, of which 97 , 103, 100, and 91 were assigned to the early-calving control (EC), early-calving synchronized (ES), late-calving control (LC), and late-calving synchronized (LS) groups, respectively. Cows were assigned to their treatment group based on odd (synchronized) and even (control) ear tag numbers. The cows were in parity $1(\mathrm{n}=$ $70), 2(n=88), 3(n=60), 4(n=32)$, or $\geq 5(n=42)$ and included 99 cows with no parity information (incomplete farm records) that were retained in the study. The parity number was similar across treatment groups. The cows were predominantly Holstein and Jersey crossbreds $(n=245)$, and there were also cows that were Holstein $(n=85)$ or Jersey $(n=61)$. Each cow was body condition scored (BCS) on a scale of 1 (emaciated) to 5 (obese) according to Edmonson et al. (1989) and vaginal mucus scored (VMS) on a scale of 0 (clear mucus) to 3 (discharge containing $\geq 50 \%$ purulent material) according to Williams et al. (2005). The distribution of BCS was $1.3,17.3,43.0,28.6,8.8$, and $1.0 \%$ for cows with BCS $2.25,2.5,2.75,3.0,3.25$, and 3.5 , respectively. The distribution of VMS was 75.0, 10.3, 2.3, and 12.4\% for cows with VMS 0, 1, 2, and 3 , respectively. The mean \pm SD DIM (minimum, maximum) at mating start date (MSD) was $85 \pm 4 \mathrm{~d}(78,92), 85 \pm 4 \mathrm{~d}(78,92)$, $36 \pm 8 \mathrm{~d}(20,49)$, and $37 \pm 8 \mathrm{~d}(20,51)$ for the EC, ES, LC, and LS groups, respectively.

The study commenced $10 \mathrm{~d}$ before MSD (Figure 1). Cows in the control groups (EC and LC) did not receive any treatment except an estrus detection patch (Estrotect, Rockway Inc., Spring Val- ley, WI) that was applied to the tail head on the day before MSD. Cows in the synchronized groups (ES and LS) were enrolled in the P4 Ovsynch Resynch protocol, which involved administration of a $100-\mu \mathrm{g}$ i.m. injection of gonadorelin hydrochloride $(\mathrm{GnRH}$, Factrel; Zoetis, New York, NY) and a controlled internal drug release (CIDR) insert containing $1.38 \mathrm{~g}$ of P4 (Eazi-Breed CIDR Cattle Insert; Zoetis), an i.m. injection of $\mathrm{PGF}_{2 \alpha}$ containing $25 \mathrm{mg}$ of dinoprost tromethamine (Lutalyse; Zoetis) coinciding with CIDR removal $7 \mathrm{~d}$ later, a second i.m. injection of GnRH $56 \mathrm{~h}$ later, followed by AI 16 h later (d 0). On d 14, each ES and LS cow received a new CIDR device, which was removed on $\mathrm{d} 21$. An estrus detection patch was also applied to the tail head of each treatment cow on $\mathrm{d} 21$. The estrus detection patches were visually assessed for activation at each milking by the farm staff. Cows were inseminated once daily at the morning milking. Control and treatment cows that returned to estrus after the morning milking on the previous day were inseminated on the next day at the morning milking. Cows in estrus during or before the morning milking on the same day were inseminated on the same day at the morning milking. Only conventional semen was used for AI.

On d 28 after MSD, a blood sample was collected from treatment cows via coccygeal venipuncture into a Monoject tube containing $\mathrm{K}_{3}$ EDTA (Covidien, Minneapolis, $\mathrm{MN}$ ) and placed on ice and transported to the laboratory within $6 \mathrm{~h}$. Samples underwent centrifugation at $1,500 \times \mathrm{g}$ for $15 \mathrm{~min}$ at $4{ }^{\circ} \mathrm{C}$, and the plasma was aspirated and stored at $-20^{\circ} \mathrm{C}$. Plasma was analyzed for pregnancy-associated glycoprotein (PAG) concentrations using the Idexx Bovine Pregnancy Test kit (Idexx, Westbrook, ME).

At $70 \mathrm{~d}$ after MSD and $84 \mathrm{~d}$ after mating end date, pregnancy diagnosis and aging of pregnancy were performed by transrectal ultrasound of uterine contents (Easi-Scan; BCF Technology USA Ltd. LLC, Rochester, MN). Conception date was determined by assessing AI dates, PAG concentrations, and ultrasound data.

Data handling and statistical analyses were performed using SAS v9.4 (SAS Institute Inc., Cary, NC). Cows with BCS 2.25 and 2.5 were coded as "low BCS," and cows with BCS 2.75 to 3.5 were coded as "target BCS." Cows with VMS 0 were coded "clear,"

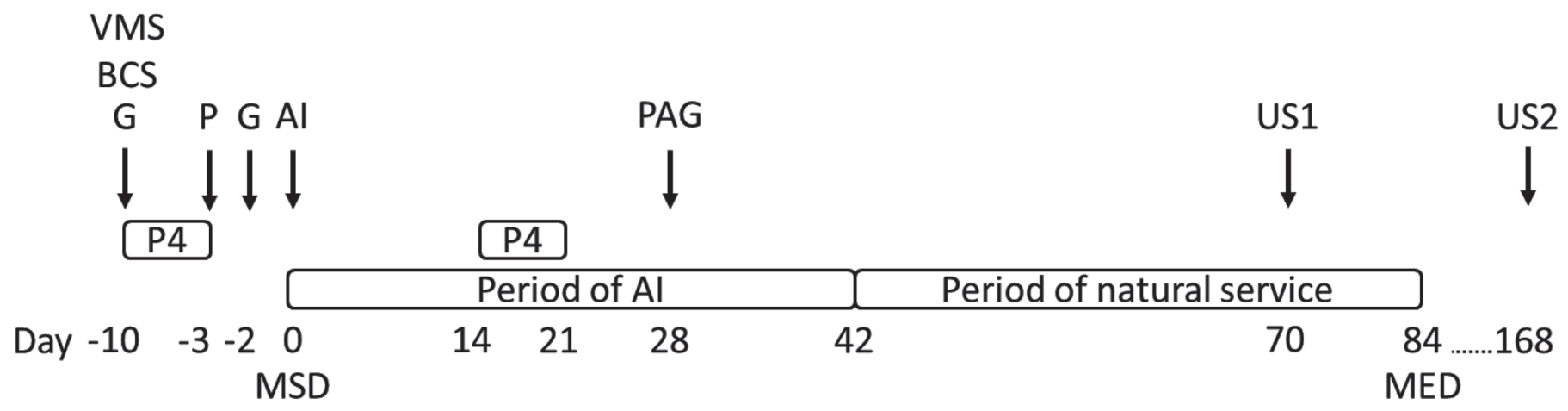

Figure 1. Diagram of the experimental activities. At $10 \mathrm{~d}$ before mating start date (MSD), vaginal mucus score (VMS) and BCS were measured, and cows were enrolled in the control group or the synchronized group [progesterone (P4) Ovsynch Resynch]. Control cows received Al after observed estrus. Cows in the P4 Ovsynch Resynch group were administered a $100-\mu \mathrm{g}$ i.m. injection of gonadorelin hydrochloride (G) and a P4 insert, an i.m. injection of PGF $2 a(P)$ coinciding with P4 insert removal $7 \mathrm{~d}$ later, a second i.m. injection of GnRH $56 \mathrm{~h}$ later, followed by Al $16 \mathrm{~h}$ later (d 0). On d 14, the P4 Ovsynch Resynch cows received a new P4 insert, which was removed on d 21. Artificial insemination continued for $42 \mathrm{~d}$ after MSD and was followed by another $42 \mathrm{~d}$ of natural service. Pregnancy was determined on d 28 by blood pregnancy-associated glycoprotein (PAG) ELISA and on d 70 (US1) after MSD and d 84 (US2) after mating end date (MED) by transrectal ultrasound of uterine contents. 
and cows with VMS 1, 2, and 3 were coded "mucopurulent." The interval from MSD to first AI was calculated as first AI date minus MSD. The interval from first AI to second AI was calculated as second AI date minus first AI date. To determine the 3-wk submission rate, cows with an interval from MSD to first $\mathrm{AI} \leq 20$ were coded as 1 ; otherwise cows were coded as 0 . To determine the 6-wk submission rate, cows with an interval from MSD to first $\mathrm{AI} \leq 41$ were coded as 1 ; otherwise cows were coded as 0 . The interval from MSD to pregnancy was calculated as the pregnancy date minus MSD. To determine the 3-wk pregnancy rate, cows with an interval from MSD to pregnancy date $\leq 20$ were coded as 1 ; otherwise cows were coded as 0 . To determine the 6 -wk pregnancy rate, cows with an interval from MSD to pregnancy date $\leq 41$ were coded as 1 ; otherwise cows were coded as 0 . To determine the 12wk pregnancy rate, cows diagnosed pregnant at the final transrectal ultrasound scan were coded as 1 ; otherwise cows were coded as 0 .

The association of cow- and farm-level factors with reproductive outcomes was tested using generalized linear mixed models with the GLIMMIX procedure. Three-week submission rate, 3-wk pregnancy rate, 6-wk pregnancy rate, and 12-wk pregnancy rate were analyzed by logistic regression with a binary distribution and the logit function specified. The interval from MSD to AI, the interval from first $\mathrm{AI}$ to second $\mathrm{AI}$, and the interval from MSD to pregnancy were analyzed by linear regression with a normal distribution, and the identity function specified. In each analysis, calving period (early, late), treatment group (control, treatment), farm (farm 1, farm 2, farm 3), BCS (low, target), VMS (clean, mucopurulent), breed, parity $(1,2,3,4, \geq 5$, unknown), and the interactions of farm $\times$ calving period and farm $\times$ treatment group were included as fixed effects with cow as a random effect. These fixed effects (excluding calving period, treatment group, and their interaction) were removed sequentially from the model beginning with the effects with the largest $P$-value and continuing until only fixed effects with $P \leq 0.1$ remained in the model. The Satterthwaite method was used to compute the denominator degrees of freedom for the tests of fixed effects. Data are presented as least squares means with Tukey-Kramer-adjusted $P$-values. Significance was deemed at $P<0.05$, and tendency was deemed at $0.05 \leq P \leq 0.1$. By design, synchronized cows received timed AI on MSD and were not included in the statistical analysis of submission rate and interval from MSD to AI. Survival analyses were also performed using the LIFETEST procedure of SAS. For each analysis, cows that were not served or did not become pregnant during the study period were right-censored at $42 \mathrm{~d}$ after MSD (i.e., the last day that breeding dates were recorded).

The proportion of cows with target BCS $(P=0.045)$ or clear vaginal mucus at $10 \mathrm{~d}$ before $\operatorname{MSD}(P=0.03)$ was greater in the early- compared with the late-calving cows but were similar between treatment groups ( $P=0.95$ and $P=0.79$, respectively). Farm was associated with the proportion of cows with target BCS $(P=$ $0.0003)$ and the proportion of cows with clear vaginal mucus at $10 \mathrm{~d}$ before $\operatorname{MSD}(P=0.02)$. The interval from MSD to AI for control cows differed between calving groups $(P=0.01$; Table 1$)$ and farms $(P=0.001)$ and exhibited a tendency between VMS $(P$ $=0.09)$. The interval from MSD to first AI was $3 \mathrm{~d}$ longer in LC compared with EC cows (14.7 vs. $11.7 \mathrm{~d}, P=0.01)$ and was $2.3 \mathrm{~d}$ longer in cows with purulent vaginal mucus score compared with cows with clear vaginal mucus (14.4 vs. $12.1 \mathrm{~d}, P=0.09)$. The differences between calving groups and treatment groups were supported by the Kaplan-Meier survival curves, as shown in Figure 2 A (log-rank $P<0.0001$, Wilcoxon $P<0.0001$ ).

The interval from first to second AI was not different between calving groups $(P=0.38)$ or treatment groups $(P=0.21)$, but a difference was associated with farm $(P=0.05)$ and a tendency with BCS group $(P=0.06)$. The interval from first AI to second AI was $2.9 \mathrm{~d}$ shorter in cows with $\mathrm{BCS} \geq 2.75$ compared with cows with

Table 1. Reproductive performance for cows calving early (ES) and late (LS) in the calving season and subjected to a control program (no treatment) or a reproductive management program based on estrous cycle synchronization and resynchronization (Synch)

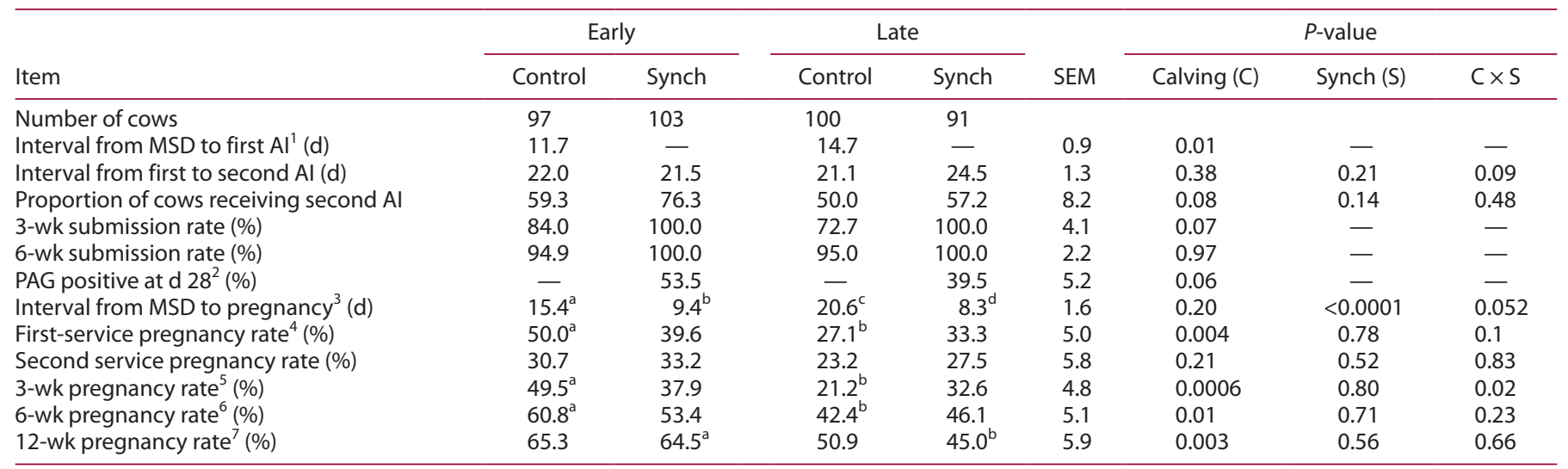

${ }^{1}$ The ES and LS cows were not included in the statistical analysis of the interval from mating start date (MSD) to first Al, the 3-wk submission rate, or the 6-wk submission rate.

${ }^{2}$ The EC and LC cows were not included in the statistical analysis of pregnancy-associated glycoprotein (PAG) positive at d 28.

${ }^{3}$ Interval from MSD to pregnancy: ${ }^{\mathrm{ab}} P=0.02,{ }^{\mathrm{ac}} P=0.099,{ }^{\mathrm{cd}} p<0.0001$.

${ }^{4}$ First service pregnancy rate: ${ }^{\mathrm{ab}} P=0.008$.

${ }^{5}$ Three-week pregnancy rate: ${ }^{\mathrm{ab}} P<0.0004$.

${ }^{6}$ Six-week pregnancy rate: ${ }^{\mathrm{ab}} P=0.054$.

${ }^{7}$ Twelve-week pregnancy rate: ${ }^{\mathrm{ab}} P=0.07$. 


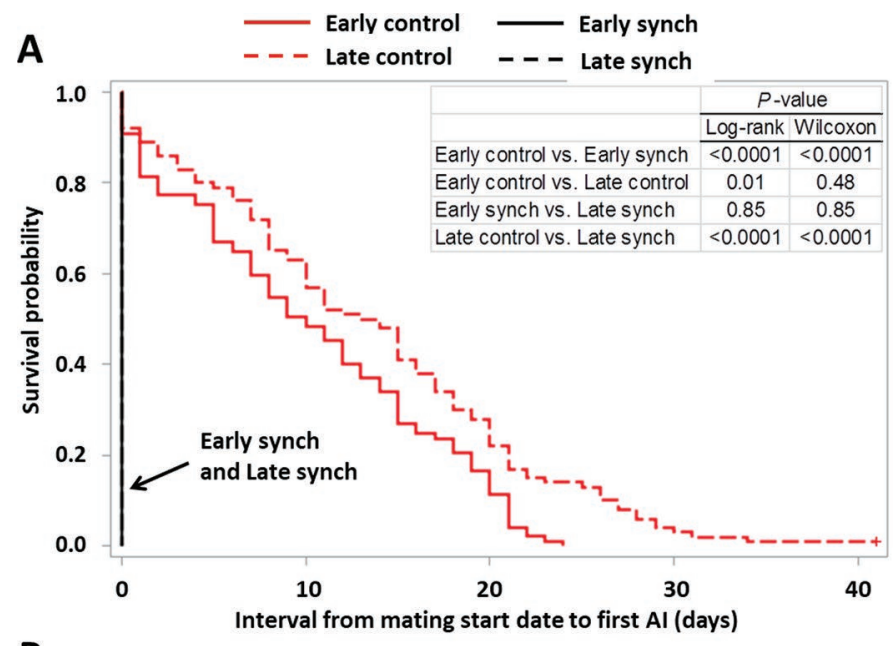

B

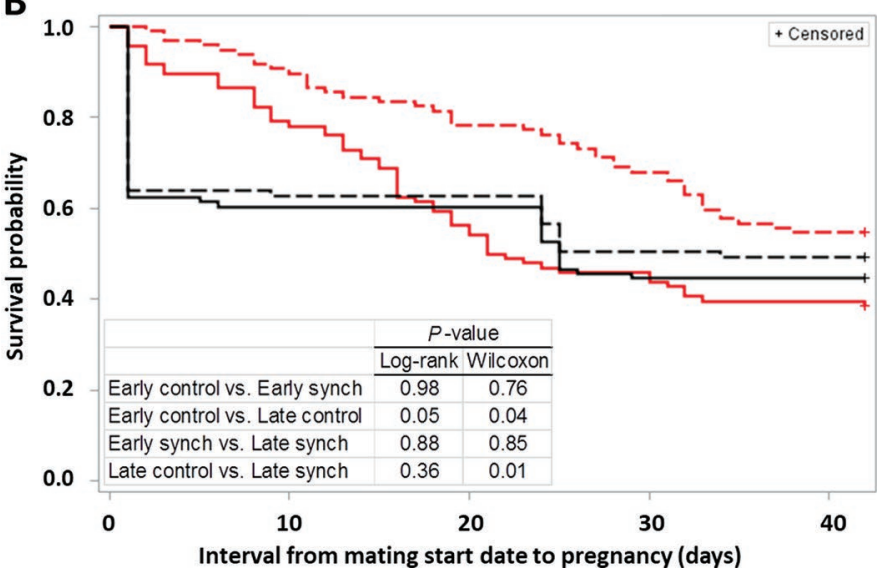

Figure 2. (A) Kaplan-Meier survival curve for effect of experimental group on mating start date (MSD) to first Al. MSD to Al differed between experimental groups (log-rank $P=0.02$, Wilcoxon $P=0.48$ ). Cows that were not submitted for Al during the first $42 \mathrm{~d}$ of the breeding season were right-censored at $42 \mathrm{~d}$. The lines for Early synch and Late synch overlap because all cows were timed $\mathrm{Al}$ (MSD to first Al =0). (B) Kaplan-Meier survival curve for effect of experimental group on MSD to pregnancy. MSD to pregnancy differed between experimental groups (log-rank $P=0.051$; Wilcoxon $P=0.002$ ). Cows that failed to become pregnant during the first $42 \mathrm{~d}$ of the breeding season were right-censored at $42 \mathrm{~d}$. Groups: Early control (early calving, no treatment); Early synch [early calving, progesterone (P4) Ovsynch Resynch]; Late control (late calving, no treatment); Late synch (late calving, P4 Ovsynch Resynch).

BCS $\leq 2.5$ (23.7 vs. $20.8 \mathrm{~d}, \mathrm{SEM}=1.4 \mathrm{~d}, P=0.06$ ). There was a tendency of calving group $(P=0.08)$, but not treatment group $(P=$ $0.14)$, to affect the proportion of cows not pregnant to the first AI that received a second AI.

The 3-wk submission rate tended to be different between calving groups $(P=0.07)$ and was different between farms $(P=0.05)$. The 3-wk submission rate tended to be greater in the EC cows compared with the LC cows ( 84 vs. $72 \%$, SEM $=4.6 \%, P=0.07$ ). There was a tendency for an interaction between farm and calving group $(P=0.07)$ for the 3 -wk submission rate. There were no differences in the 6-wk submission rate between the EC and LC cows $(P=0.97)$.
Pregnancy rate to first AI tended to be greater in the early-calving cows compared with the late-calving cows when assessed at 28 $\mathrm{d}$ after MSD using the blood PAG pregnancy test (synchronized cows only, 53.5 vs. $39.5 \%, \mathrm{SEM}=5.2 \%, P=0.06$ ) and was greater at $70 \mathrm{~d}$ after MSD when diagnosed by transrectal ultrasound of uterine contents (control and synchronized cows, 44.7 vs. $30.1 \%$, $\mathrm{SEM}=3.5 \%, P=0.004)$. There was a tendency for a calving $\times$ treatment interaction $(P=0.1)$, likely influenced by the significance of the pregnancy rate to first AI between EC cows and LC cows $(P=0.01)$ and lack of difference between the ES cows and the LS cows $(P=0.82)$. There were no differences in pregnancy rate to second AI between calving groups $(P=0.21)$ and treatment groups $(P=0.51)$, but there was an effect of farm $(P<0.0001)$.

Both the 3 -wk pregnancy rate (43.6 vs. $26.5 \%, \mathrm{SEM}=3.4 \%$, $P=0.0006)$ and 6 -wk pregnancy rate $(57.2$ vs. $44.2 \%, \mathrm{SEM}=$ $3.6 \%, P=0.01)$ were greater in early-calving cows compared with late-calving cows, but the differences between control cows and synchronized cows were not significant $(P=0.8$ and $P=0.7$, respectively). The 3 -wk pregnancy rate was affected by a calving $\times$ treatment interaction $(P=0.01)$ because the differences between the EC and LC $(P=0.001)$, but not between the ES cows and LS cows $(P=0.30)$, were significant.

The 12-wk pregnancy rate as determined by transrectal ultrasound $84 \mathrm{~d}$ after mating end date was greater in the early-calving cows than in the late-calving cows ( 64.9 vs. $48.0 \%, \mathrm{SEM}=4.2 \%, P$ $=0.003$ ) and was greater in cows with clear versus purulent vaginal mucus $10 \mathrm{~d}$ before MSD (63.0 vs. 50.1\%, SEM =4.4\%, $P=0.04$ ).

The interval from MSD to pregnancy was shorter in the treated cows than in the control cows $(8.8$ vs. $18.0 \mathrm{~d}, \mathrm{SEM}=1.2 \mathrm{~d}, P<$ $0.0001)$ but was similar between the early-calving cows and the late-calving cows (12.4 vs. $14.5 \mathrm{~d}, \mathrm{SEM}=1.1 \mathrm{~d}, P=0.2)$; there was a calving $\times$ treatment interaction $(P=0.052)$. The differences between calving groups and treatment groups were supported by the Kaplan-Meier survival curves, as shown in Figure 2B (log-rank $P<0.0001$, Wilcoxon $P<0.0001)$.

In both the early-calving cows and the late-calving cows, the P4 Ovsynch Resynch protocol reduced the interval from MSD to pregnancy by 6 and $12 \mathrm{~d}$, respectively, compared with the nonsynchronized cows. These results represented a major improvement in the reproductive performance of the cows enrolled in the P4 Ovsynch Resynch protocol compared with the control cows, particularly for late-calving cows. Our primary hypothesis was, therefore, supported (improved reproduction in synchronized cows regardless of their calving group). A unique aspect of the current study was that late-calving cows with a minimum 10 DIM were eligible to be enrolled. Typically, early postpartum cows are not enrolled in estrous synchronization studies because maximum fertility is not achieved until around 60 DIM at AI (Herlihy et al., 2013). Although pregnancy rates were less in late-calving cows than in early-calving cows, pregnancies were achieved in LC and LS cows as early as 22 and 20 DIM, respectively. These results suggest that all cows at least 20 DIM should be eligible for AI from MSD.

The lesser DIM at MSD for late- compared with EC cows was associated with a 3-d-longer interval from MSD to first AI, an 11-percentage-point reduction in 3-wk submission rate, and a 5-dlonger interval from MSD to the establishment of pregnancy. These differences were not evident in the synchronized cows, particularly as the interval from MSD to pregnancy, 3-wk pregnancy rate, and 
6-wk pregnancy rate were similar in the ES and LS cows. Although late-calving cows are undesirable, they can nonetheless be managed. It is likely that fewer LC cows had resumed estrous cyclicity and expression compared with EC cows. The greater pregnancy rates in the EC cows compared with the LC cows were also likely due to a greater proportion of the EC cows being at target BCS and having clear vaginal mucus at $10 \mathrm{~d}$ before MSD, in agreement with Rojas Canadas et al. (2020). Reduced pregnancy rates in latecalving, pasture-based cows were also reported by Escalante et al. (2013) and Rojas Canadas et al. (2020).

Similar to the current study, Escalante et al. (2013) reported that pasture-based dairy cows in the southwest region of Missouri had reduced pregnancy rates at second AI compared with first AI. That study compared the reproductive performance of dairy cows submitted for AI after observed estrus or enrolled in a protocol consisting of the presynchronization of the estrous cycle with a P4 insert for $14 \mathrm{~d}$ before timed AI. In an attempt to increase submission rates and pregnancy rates for second $\mathrm{AI}$ in nonpregnant cows, we administered a new P4 device from d 14 to 21 after the first timed AI using an approach similar to that reported by Ribeiro et al. (2011). This was done to prevent nonpregnant cows from displaying estrus before $\mathrm{d} 21$, thereby reducing the period of time required for estrous detection. Neither the proportion of cows that received a second AI nor the interval from the first $\mathrm{AI}$ to the second AI was improved in the treated compared with control cows. Overall, $60 \%$ of the cows that were not pregnant to the first AI received a second AI. This very low percentage highlights the difficulty that the 3 farms had rebreeding dairy cows based on either low levels of estrous expression or low levels of estrous detection. In agreement with Ribeiro et al. (2011), the use of a P4 device to improve the resynchronization of estrus for the second $\mathrm{AI}$ and pregnancy rate was not successful.

Pregnancy rates in the late-calving cows did not improve for the second AI compared with the first AI even though there was a 21- to 24-d increase in DIM. Also, the pregnancy rate in the EC cows and the ES cows decreased from 50.0 to $30.7 \%$ and from 39.6 to $33.2 \%$ for the first AI compared with the second AI, respectively (Table 1). The low pregnancy rate to second AI may be, in part, a consequence of the greater ambient temperatures that pasture-based dairy cows in the southwest region of Missouri are typically exposed to in June $\left(23^{\circ} \mathrm{C}\right)$ compared with May $\left(18^{\circ} \mathrm{C}\right)$ (https://www.weather.gov/sgf/climate_sgf_monthly_normals) or because the proportion of cows with lesser fertility increased in the remaining nonpregnant population of cows. Although producers are hesitant to increase their investment in reproductive technologies, resynchronization protocols with $100 \%$ timed AI of nonpregnant cows should be considered when submission rates are low. Economic simulation models demonstrate greater profitability for cows intensively managed with timed AI (Ricci et al., 2020).

Across all experimental groups, BCS, VMS, and farm were associated with differences in reproductive performance. As previously reported by Løvendahl and Chagunda (2010) and Madureira et al. (2015), thin cows had longer intervals from calving to first estrus and had shorter, less intense periods of estrous expression. Although the current study did not find any association between BCS and the interval to first AI, the interval from first AI to second AI was approximately $3 \mathrm{~d}$ longer in cows with a $\mathrm{BCS} \leq 2.5 \mathrm{com}-$ pared with cows with $\mathrm{BCS} \geq 2.75$. When considered together, these studies strongly support the existence of a biological mechanism whereby the estrous cycle and estrous expression are affected by BCS. Vaginal mucus scores reflect the level of uterine bacterial growth (Williams et al., 2005), and the negative association between purulent vaginal mucus and longer interval from MSD to first AI and reduced 12-wk pregnancy rate in the current study is supported by others (Williams et al., 2005).

The results of the current study provide evidence for reduced reproductive performance of late-calving cows compared with earlycalving cows. The study also demonstrated the major improvement in reproductive performance that can be achieved by targeting latecalving cows with the P4 Ovsynch Resynch protocol, even when cows are only 20 to 50 DIM at first AI. Although late-calving cows are undesirable, they can nonetheless be managed. Resynchronization of estrus with a progesterone device only, however, was not sufficient to increase the proportion of nonpregnant cows that received a second AI. Further improvements to the management of late-calving cows could be achieved through systems that used timed $\mathrm{AI}$ at both first and second insemination.

\section{References}

Britt, J. H. 1975. Early postpartum breeding in dairy cows: A review. J. Dairy Sci. 58:266-271. https://doi.org/10.3168/jds.S0022-0302(75)84558-9.

Butler, S. T. 2014. Nutritional management to optimize fertility of dairy cows in pasture-based systems. Animal 8(Suppl. 1):15-26. https://doi.org/10.1017/ S1751731114000834.

Chebel, R. C., J. E. P. Santos, R. L. A. Cerri, H. M. Rutigliano, and R. G. S. Bruno. 2006. Reproduction in dairy cows following progesterone insert presynchronization and resynchronization protocols. J. Dairy Sci. 89:4205-4219. https://doi.org/10.3168/jds.S0022-0302(06)72466-3.

Chenault, J. R., J. F. Boucher, K. J. Dame, J. A. Meyer, and S. L. Wood-Follis. 2003. Intravaginal progesterone insert to synchronize return to estrus of previously inseminated dairy cows. J. Dairy Sci. 86:2039-2049. https://doi .org/10.3168/jds.S0022-0302(03)73793-X.

Cordoba, M. C., and P. M. Fricke. 2002. Initiation of the breeding season in a grazing-based dairy by synchronization of ovulation. J. Dairy Sci. 85:1752-1763. https://doi.org/10.3168/jds.S0022-0302(02)74249-5.

Edmonson, A. J., I. J. Lean, L. D. Weaver, T. Farver, and G. Webster. 1989. A body condition scoring chart for Holstein dairy cows. J. Dairy Sci. 72:68-78. https://doi.org/10.3168/jds.S0022-0302(89)79081-0.

Escalante, R. C., S. E. Poock, D. J. Mathew, W. R. Martin, E. M. Newsom, S. A. Hamilton, K. G. Pohler, and M. C. Lucy. 2013. Reproduction in grazing dairy cows treated with 14-day controlled internal drug release for presynchronization before timed artificial insemination compared with artificial insemination after observed estrus. J. Dairy Sci. 96:300-306. https://doi .org/10.3168/jds.2012-5853.

Herlihy, M. M., D. P. Berry, M. A. Crowe, M. G. Diskin, and S. T. Butler. 2011. Evaluation of protocols to synchronize estrus and ovulation in seasonal calving pasture-based dairy production systems. J. Dairy Sci. 94:4488-4501. https://doi.org/10.3168/jds.2010-4126.

Herlihy, M. M., M. A. Crowe, D. P. Berry, M. G. Diskin, and S. T. Butler. 2013. Factors associated with fertility outcomes in cows treated with protocols to synchronize estrus and ovulation in seasonal-calving, pasture-based dairy production systems. J. Dairy Sci. 96:1485-1498. https://doi.org/10.3168/ jds.2011-5250.

Løvendahl, P., and M. G. G. Chagunda. 2010. On the use of physical activity monitoring for estrus detection in dairy cows. J. Dairy Sci. 93:249-259. https://doi.org/10.3168/jds.2008-1721.

Madureira, A. M. L., B. F. Silper, T. A. Burnett, L. Polsky, L. H. Cruppe, D. M. Veira, J. L. M. Vasconcelos, and R. L. A. Cerri. 2015. Factors affecting expression of estrus measured by activity monitors and conception risk of lactating dairy cows. J. Dairy Sci. 98:7003-7014. https://doi.org/10.3168/ jds.2015-9672.

Ribeiro, E. S., R. L. A. Cerri, R. S. Bisinotto, F. S. Lima, F. T. Silvestre, L. F. Greco, W. W. Thatcher, and J. E. P. Santos. 2011. Reproductive performance of grazing dairy cows following presynchronization and resynchro- 
nization protocols. J. Dairy Sci. 94:4984-4996. https://doi.org/10.3168/jds .2011-4225.

Ricci, A., M. Li, P. M. Fricke, and V. E. Cabrera. 2020. Short communication Economic impact among 7 reproductive programs for lactating dairy cows, including a sensitivity analysis of the cost of hormonal treatments. J. Dairy Sci. 103:5654-5661. https://doi.org/10.3168/jds.2019-17658.

Rojas Canadas, E., M. Gobikrushanth, P. Fernandez, J. Kenneally, P. Lonergan, and S. T. Butler. 2019. Evaluation of alternative strategies to treat anoestrous dairy cows and implications for reproductive performance in pasturebased seasonal calving herds: A pilot study. Theriogenology 127:130-136. https://doi.org/10.1016/j.theriogenology.2019.01.008.

Rojas Canadas, E., M. M. Herlihy, J. Kenneally, J. Grant, F. Kearney, P. Lonergan, and S. T. Butler. 2020. Associations between postpartum phenotypes, cow factors, genetic traits, and reproductive performance in seasonalcalving, pasture-based lactating dairy cows. J. Dairy Sci. 103:1016-1030. https://doi.org/10.3168/jds.2018-16001.

Shalloo, L., A. Cromie, and N. McHugh. 2014. Effect of fertility on the economics of pasture-based dairy systems. Animal 8(Suppl. 1):222-231. https: //doi.org/10.1017/S1751731114000615.

Thatcher, W. W., and C. J. Wilcox. 1973. Postpartum estrus as an indicator of reproductive status in the dairy cow. J. Dairy Sci. 56:608-610. https://doi .org/10.3168/jds.S0022-0302(73)85227-0.
Williams, E. J., D. P. Fischer, D. U. Pfeiffer, G. C. W. England, D. E. Noakes, H. Dobson, and I. M. Sheldon. 2005. Clinical evaluation of postpartum vaginal mucus reflects uterine bacterial infection and the immune response in cattle. Theriogenology 63:102-117. https://doi.org/10.1016/j .theriogenology.2004.03.017.

\section{Notes}

S. G. Moore (1) https://orcid.org/0000-0001-9896-8519

R. Molina-Coto ๑ https://orcid.org/0000-0003-3844-2587

L. M. Mayo $\odot$ https://orcid.org/0000-0002-2750-7894

R. O. Rodrigues $\odot$ https://orcid.org/0000-0001-5669-3414

S. E. Poock @ https://orcid.org/0000-0003-1178-0316

M. C. Lucy @ https://orcid.org/0000-0001-5771-9460

The authors thank the farm owners and the farm staff for collaboration on the trial. The authors thank Zoetis (New York, NY) for donating the pharmaceuticals used in the trial.

The authors have not stated any conflicts of interest. 